\title{
A novel way to deal with challenge and fear of smoke and gas evacuation during minimal invasive surgery in the current era of COVID-19 pandemic: an ingenuity with review of literature
}

\author{
Kaptan Singh $^{1 *}$, Atul S. Joshi ${ }^{1}$, Agrawal K. Khemchand ${ }^{2}$, Hariom Sheoran ${ }^{1}$, Priti Rabadiya ${ }^{1}$
}

${ }^{1}$ Department of Surgery, Fortis hospital, Mohali, Punjab, India

${ }^{2}$ Department of casualty, Postgraduate institute of medical education and research, Chandigarh, India

Received: 19 May 2020

Accepted: 04 July 2020

\author{
*Correspondence: \\ Dr. Kaptan Singh, \\ E-mail: kaptanpgi2k12@gmail.com
}

Copyright: (C) the author(s), publisher and licensee Medip Academy. This is an open-access article distributed under the terms of the Creative Commons Attribution Non-Commercial License, which permits unrestricted non-commercial use, distribution, and reproduction in any medium, provided the original work is properly cited.

\begin{abstract}
Presently COVID-19 viral transmission is a major concern among surgeons worldwide with the use of minimally invasive surgery due to creation of pneumoperitoneum. Due to this proposed concern, we sought to review the scientific data, evaluate the use of MIS and introduction of a novel concept to deal with surgical smoke and gas to prevent the risk of COVID-19 viral transmission. A review of literature of viral transmission in surgery, especially emphasizing the transmission of the COVID-19 was done. We also reviewed other surgical society guidelines and recommendations regarding surgery during this pandemic. Few studies have been performed on viral transmission during surgery, but to date there is not enough evidence to support use of MIS over open surgery or vice versa. There are societal guidelines and expert consensus on the modification of standard practices to minimize the risk of viral transmission. With every day rise in COVID-19 patients therefore consequent increase in surgeries in suspected or confirmed cases and exposure of operative staff to aerosolized particles during MIS, use of surgical smoke and gas evacuation system becomes essential. Although different available filters, insufflation systems are part of the surgical procedures but their cost and availability may concern a COVID-19 fighting or a developing nation. We introduced a novel, simple, easily available and cost effective technique to prevent and reduce the risk of viral transmission in the current era of COVID-19 pandemic.
\end{abstract}

Keywords: COVID-19 pandemic, Minimally invasive surgery, SARS-CoV-2, Smoke evacuation

\section{INTRODUCTION}

Currently COVID-19 disease is embracing the whole world. COVID-19 is caused by a novel human coronavirus that is now named severe acute respiratory syndrome coronavirus 2 (SARS-CoV-2, formerly called HCoV-19) emerged in Wuhan, China, in late 2019. ${ }^{1}$ The World Health Organization declared COVID-19 as pandemic on 11 March 2020. The novel coronavirus pandemic is the current most discussed topic, both by the popular imagery and media, as well as by the scientific world. It is stated that this disease has a geometric capacity of dissemination and a tremendous global socioeconomic impact. The disease has strongly influenced everyone's daily routine. Mandatorily social isolation rules, the closing of national borders, and planning for disaster health care initiatives have permeated the current news worldwide. There is no doubt that COVID-19 has become part of everybody's daily life with unprecedented conditions. The virus responsible for COVID-19 (SARS-CoV-2) belongs to the subgroup of coronaviruses that include the severe acute respiratory syndrome coronavirus (SARS- CoV) and the Middle East respiratory syndrome coronavirus (MERS-CoV). Although very similar to these viruses, COVID-19 appears to be highly contagious due to its longer latency 
period. The only current known modality of transmission of the COVID-19 virus is through respiratory droplet transmission. ${ }^{2,3}$ The size of these viral particles themselves ranges from 0.07 to $0.09 \mu \mathrm{m}$, which however are transmitted through droplet particles. ${ }^{4}$ The mechanism for successful transmission of these droplets is by 1) direct human to human 2) contaminated surfaces 3) a proposed mechanism suggested, although sufficient evidence is lacking, that an aerosolizing procedure on an infected person.

However, since the only proven mode of transmission of COVID-19 is through respiratory droplets, the risk of transmission from the abdomen is unclear. A study performed during the SARS outbreak in 2003 showed that droplets from infected patients could reach people located two meters or more from the source. ${ }^{5}$ In addition, experience from the SARS epidemics demonstrated the presence of coronavirus in stool samples and intestinal biopsy samples. ${ }^{6}$ Recently, it has been confirmed that COVID-19 can be found in the oral cavity and faecal samples of infected individuals. ${ }^{7-10}$ Among surgeons around the world, a proposed theoretical risk of viral transmission with the use of MIS has been raised in the setting of COVID-19. This concern has arisen from not only the discovery that COVID-19 virus RNA can be found in the stool of infected patients but the suggestion that the virus can be found in the gastrointestinal mucosa. ${ }^{11,12}$ Thus, despite the lack of evidence to demonstrate or refute the viral transmissibility from the gastrointestinal tract, a threat that the virus can be transmitted from the abdomen exists. ${ }^{12}$ It has been also theorized that the environment created by pneumoperitoneum for laparoscopy creates a relatively stagnant heated volume of gas in the abdominal cavity, which may subsequently allow for a concentrated aerosolization of the virus. Thus, it is hypothesized that sudden bursts of this pneumoperitoneum from trocar valves during exchange of instruments or during the venting of trocars can allow for transmission of the virus.

\section{OPEN VERSUS MINIMAL INVASIVE SURGERY IN COVID-19 ERA}

Currently there is little or no evidence suggesting open over MIS or vice-versa specifically for COVID 19 virus transmission. This might be due to pandemic spread over a short span of time and restrictions over elective surgeries. However consideration be given to the possibility of viral contamination to staff during either open or MIS and protective measures should strictly employed for OR staff. Proven benefits of MIS of reduced length of stay and complications should be strongly considered in these patients, in addition to the potential for ultrafiltration of the majority or all aerosolized particles. Filtration of aerosolized particles may be more difficult during open surgery. In MIS, an essential part of the procedure is the establishment and maintenance of an artificial pneumoperitoneum that imposes the risk of aerosol exposure to the OR team.
Commonly used electrosurgical devices produce large amount of surgical smoke, which needs to be evacuated to maintain a clear field of surgery therefore producing an inadvertent risk of contamination to the OR team. In earlier studies, activated corynebacterium, papillomavirus and HIV have been detected in surgical smoke. ${ }^{13-15}$ Several health care workers contracted a rare papillomavirus that is suspected to be connected to surgical smoke exposure. ${ }^{16}$ The risk of COVID-19 novel virus infection should not be any exception. One study found that after using electrical or ultrasonic equipment for 10 minutes, the particle concentration of the smoke in laparoscopic surgery was significantly higher than that in traditional open surgery. ${ }^{17}$ The reason may be that due to the low gas mobility in the pneumoperitoneum, the aerosol formed during the operation tends to concentrate in the abdominal cavity. Sudden release of trocar valves, non-air-tight exchange of instruments or even small abdominal extraction incisions can potentially expose the health care team to the pneumoperitoneum aerosol. This outbreak thus poses a great challenge to the clinical work of surgeons who practice MIS.

\section{MEASURES TO PREVENT EXPOSURE TO SURGICAL SMOKE}

Recently, SAGES in conjunction with EAES, published guidelines for surgeons concerning the use of MIS during the current COVID-19 pandemic. Filtration may be an effective means of protection from the release of virus during MIS. Masks such as N95 respirators are designed to filter out $95 \%$ particles that are 0.3 microns and larger. Several different insufflation systems also exist. The common system that has been suggested for use during this COVID-19 pandemic is ConMed AirSeal ${ }^{\circledR}$. One of the first sophisticated insufflator systems, this device uses an intelligent flow system control unit. ${ }^{18}$ The PneumoClear is another integrated insufflator with smoke evacuation system similar to that of the AirSeal ${ }^{\circledR}$ with a dual-lumen tubing set except it uses traditional trocars. Other commercially available widely used independent smoke evacuation systems are N95 respirator, ConMed PlumePort ActiV, Stryker PureView Active Plume. When a smoke evacuation system is not available, several groups have described using direct suction to laparoscopic trocars to allow for evacuation of the smoke. These systems can be integrated with the use of filters removed from endotracheal tubes or other devices; however, this method cannot guarantee the high filtration efficiency of the manufactured smoke evacuation devices. Powered air purifying respirators (PAPR), highefficiency particulate air (HEPA) filters, ultra-low particulate air (ULPA) filters are different available devices with different effectiveness for each.

\section{HOW DIFFERENT WE DID ON EVIDENCE BASED LITERATURE?}

The concept of antimicrobial properties of iodine was implemented to prevent direct smoke evacuation during 
MIS. In Povidone iodine, iodine forms a complex with the synthetic carrier polymer Povidone, which itself has no microbicidal activity. ${ }^{19}$ In an aqueous medium, free iodine is released into solution from the Povidone iodine complex and equilibrium is established, with more free iodine being released from the povidone iodine reservoir as iodine-consuming germicidal activity proceeds..$^{20,21} \mathrm{~A}$ decade earlier, a study by Sriwilaijaroen et al examined Povidone-iodine, which has a broad-spectrum microbicidal property for its inhibitory effects against influenza virus infection in MDCK cells and the mechanisms of action on hemagglutinin and neuraminidase were revealed. ${ }^{22}$

Results obtained using a novel fluorescence and chromogenic-based plaque inhibition assay showed that $1.56 \mathrm{mg} / \mathrm{ml}$ Povidone iodine inhibited infections in MDCK cells of human ( 8 strains) and avian (5 strains) influenza A viruses, including H1N1, H3N2, H5N3 and H9N2, from 23.0-97.5\%. They concluded that Povidone iodine, for which there has been no report of resistance, is a potential agent that not only prevents viral infections but also reduces the spread of influenza viruses in epidemic and pandemic areas. Another study by Eggers et al showed Povidone iodine gargle/mouthwash diluted to $1: 30$ (equivalent to a concentration of $0.23 \%$ ) showed effective bactericidal activity against Klebsiella pneumonia, Streptococcus pneumoniae and rapidly inactivated SARS-CoV, MERS- CoV, influenza virus A (H1N1) and rotavirus after 15 seconds of exposure. ${ }^{23}$

Intercostal tube drainage bag was another important asset. ICD bag is specially designed to escape the air/gas from a closed system. 10\% Povidone-iodine solution was put in ICD bag upto the mark over bag before starting the procedure. Pneumoperitoneum was created with classic closed technique using Veress needle. All other ports were placed subsequently. One of the ports was connected to the ICD bag containing Povidone iodine hence creating a closed system. This port was opened intermittently during electrocoagulation to escape the smoke, which was conveyed to the Povidone iodine solution via ICD channel. After completion of the procedure, all the gas was allowed to escape via this closed system followed by extraction of the specimen and removal of other ports subsequently.

\section{FUTURE PROSPECTIVE}

Currently whole world is occupied by the COVID-19 curse with the economy being at its lower end. India is a developing nation. It is the $2^{\text {nd }}$ largest populous country covering nearly $17.35 \%$ of world's population. Therefore in a country like India or an emerging nation from COVID-19 outbreak where the economy is regaining its pace, the described simple, easily available and cost effective technique of smoke evacuation during MIS may solve the problem of fear, cost and availability.
Based on our review of the current scientific knowledge, there is not enough evidence to support use of MIS over open surgery or vice versa to reduce viral transmission of COVID-19. However, there is still much to learn about the disease and transmission during surgery. We understand the theoretical risk of viral transmission from the abdomen of an infected individual during either open or MIS. Where MIS is preferred, the gas and smoke evacuation from pneumoperitoneum is a matter of concern for every health care provider in OR. We introduce and propose the described novel, simple, easily available and cost effective technique for smoke and gas evacuation during MIS where an insufflation system is available or not. This technique may be of low or debatable benefit; however, smoke and gas evacuation mechanism should be considered for all confirmed or suspected cases of COVID-19.

\section{Funding: No funding sources \\ Conflict of interest: None declared \\ Ethical approval: Not required}

\section{REFERENCES}

1. Coronavirus disease (COVID-2019) situation reports. Geneva: World Health Organization, 2020. Available at: https://www.who.int/ emergencies/diseases/novel-coronavirus2019/situation-reports/.

2. Ong SW, Tan YK, Chia PY, Lee TH, Ng OT, Wong MS, et al. Air, surface environmental, and personal protective equipment contamination by severe acute respiratory syndrome coronavirus 2 (SARS-CoV-2) from a symptomatic patient. JAMA. 2020;323(16):1610-2.

3. Wu D, Wu T, Liu Q, Yang Z. The SARS-CoV-2 outbreak: what we know. Int $\mathrm{J}$ Infect Dis. 2020;94:44-8.

4. Kim JM, Chung YS, Jo HJ, Lee NJ, Kim MS, Woo $\mathrm{SH}$, et al. Identification of coronavirus isolated from a patient in Korea with COVID-19. Osong Public Health Res Perspect. 2020;11(1):3-7.

5. Wong TW, Lee CK, Tam W, Lau JT, Yu TS, Lui $\mathrm{SF}$, et al. Cluster of SARS among medical students exposed to single patient, Hong Kong. Emerg Infect Dis. 2004;10(2):269-76.

6. Leung WK, To KF, Chan PK, Chan HL, Wu AK, Lee $\mathrm{N}$, et al. Enteric involvement of severe acute respiratory syndrome-associated coronavirus infection. Gastroenterology. 2003;125(4):1011-7.

7. Gu J, Han B, Wang J. COVID-19: gastrointestinal manifestations and potential fecal-oral transmission. Gastroenterology. 2020;158(6):1518-9.

8. Song Y, Liu P, Shi XL, Chu YL, Zhang J, Xia J, et al. SARS-CoV-2 induced diarrhoea as onset symptom in patient with COVID-19. Gut. 2020;69(6):1143-4.

9. Zhang J, Wang S, Xue Y. Fecal specimen diagnosis 2019 novel coronavirus-infected pneumonia. J Med Virol. 2020;92(6):680-2.

\section{CONCLUSION}


10. Xiao F, Tang M, Zheng X, Liu Y, Li X, Shan H. Evidence for gastrointestinal infection of SARSCoV-2. Gastroenterology. 2020;158(6):1831-3.

11. Capizzi PJ, Clay RP, Battey MJ. Microbiologic activity in laser resurfacing plume and debris. Lasers Surg Med. 1998;23(3):172-4.

12. Xiao F, Tang M, Zheng X, Liu Y, Li X, Shan H. Evidence for gastrointestinal infection of SARSCoV-2. Gastroenterology. 2020;158(6):1831-3.

13. Capizzi PJ, Clay RP, Battey MJ. Microbiologic activity in laser resurfacing plume and debris. Lasers Surg Med. 1998;23(3):172-4.

14. Hensman C. Chemical composition of smoke produced by high-frequency electrosurgery in a closed gaseous environment. Surg Endosc. 1998;12(8):1017-9.

15. Johnson GK, Robinson WS. Human immunodeficiency virus-1 (HIV-1) in the vapors of surgical power instruments. J Med Virol. 1991;33(1):47-50.

16. Gloster HM, Roenigk RK. Risk of acquiring human papillomavirus from the plume produced by the carbon dioxide laser in the treatment of warts. J Am Acad Dermatol. 1995;32:436-441

17. Li CI, Pai JY, Chen CH. Characterization of smoke generated during the use of surgical knife in laparotomy surgeries. J Air Waste Manag Assoc. 2020;70(3):324-32.

18. Annino F, Topazio L, Autieri D, Verdacchi T, De Angelis M, Asimakopoulos AD. Robotic partial nephrectomy performed with Airseal versus a standard CO. Surg Endosc. 2017;31(4):1583-90.
19. Ripa S, Bruno N, Reder RF, Casillis R, Roth RI. Clinical applications of povidone-iodine as a topical antimicrobial. In: Handbook of topical antimicrobials: industrial applications in consumer products and pharmaceuticals. Marcel Dekker; 2003:77-98.

20. Fleischer W, Reimer K. Povidone-iodine in antisepsis estate of the art. Dermatology. 1997;195(2):3-9.

21. Rackur H. New aspects of mechanism of action of Povidone-iodine, J Hosp Infect. 1985;6(A):13-23.

22. Sriwilaijaroen $N$, Wilairat $P$, Hiramatsu $H$, Takahashi T, Suzuki T, Ito M, et al. Mechanisms of the action of povidone-iodine against human and avian influenza A viruses: its effects on hemagglutination and sialidase activities. Virol J. 2009;6(1):124.

23. Eggers M, Koburger-Janssen T, Eickmann M, Zorn J. In vitro bactericidal and virucidal efficacy of povidone-iodine gargle/mouthwash against respiratory and oral tract pathogens. Infect Dis Therap. 2018;7(2):249-59.

Cite this article as: Singh K, Joshi AS, Khemchand AK, Sheoran H, Rabadiya P. A novel way to deal with challenge and fear of smoke and gas evacuation during minimal invasive surgery in the current era of COVID-19 pandemic: an ingenuity with review of literature. Int Surg J 2020;7:2814-7. 